\title{
The Study on the Effect of Background Music on Customer Waiting Time in Restaurant
}

\author{
Zhou Fang*
}

Anyang Normal University, China

\begin{abstract}
Many scholars study shows that the background music is restaurant controllable environmental factor that can affect the customer waiting time, which has some management implications for solving customer wait time problem in the service sector. This article used experimental management method, randomly selected a large restaurant, and then observed each customer just coming in, recorded background music types (including no music, slow-paced and fast-paced) and customer waiting time. And we made comparative analysis of the differences between weekdays and weekends. Finally, the experimental results and analysis are given: (1) Background music can really affect the customer's waiting time; (2) Slow-paced background music can extend the customer waiting time, meanwhile fast-paced background music will shorten the waiting time of customers; (3) On weekends average waiting time is longer than working day.
\end{abstract}

Keywords: Background music, customer, management experiment, waiting time.

\section{INTRODUCTION}

Latency is a key factor in consumer evaluation services. In terms of catering, restaurant serving slowly is an important factor causing customer waiting time. Customer waiting too long will lead to customer dissatisfaction to restaurant service, thereby affecting the entire customer satisfaction, and ultimately affect the restaurant's operating results. Many scholars study shows that the background music is restaurant controllable environmental factor that can affect the customer waiting time, which has some management implications for solving customer wait time problem in the service sector. Hue quad University experiment restaurant is a restaurant open for business entities [1]. The restaurant serving slowly is the management bottlenecks. Improves serving speed is not only a problem very difficult to solve of the restaurant, but also the entire restaurant industry [2].

In recent years, consumers are starting to pay attention to the experience of eating process, hoping to be integrated with dining and entertainment. So the service environment has become the focus of the attention of the manager [3]. The music is one of the important factors in the environment, and many foreign scholars have been focused on the research in this field for long. However, research in this field for the domestic is blank [4].

Currently, the vast majority of Chinese restaurants began to play background music, to create the restaurant's ambience, and to achieve a certain marketing purposes. But the choice of music is more by the intuition or experience of their marketing manager, even or broadcast studios employees' personal preferences, and there is no scientific basis for empirical research. Planning Director of Meyer consultants business Rick let once said: "If music is just the right, then formats a cultural, otherwise it becomes a noise." So no scientific basis can lead to the background music mixed, and sometimes even counterproductive. So how to choose the music, choose what kind of music and how to play music become the problems marketing managers need to pay attention to and solve [5].

The rest of the paper is organized as follows. In Section 2 , background music is summarized briefly. In Section 3, the data processing method is described. In Section 4, experiments are presented and the results are discussed. Finally, a conclusion is provided in Section 5.

\section{BACKGROUND MUSIC}

About define background music, a number of scholars give many definition according to its own research scenario. Yang and span gen berg divided music into foreground music and background music according to the presence or absence of performers and other factors lyrics [6]. Foreground music has a specific performer and lyrics. The background music is the music musicians played with no specific number of performers without words. At the same time, the background music have strict restrictions in rhythm, frequency range and volume. The Park and Young believe that the presence of lyrics had nothing to do with background music. Music used to render the atmosphere can be called background music [7].

Based on the previous definition of background music, in this study, the background music is defined as the instrumental music with non-specific lyrics and performers, used to render the atmosphere. Background music should be used properly; the effect can be just the right. There are two background music utility. First, psychologically cover ambient noise. The volume is small, if not concentrate on listening; 
you cannot distinguish the sound source location. The second is to create harmonious relaxed atmosphere matched the indoor environment [8].

With the homogenization of increasingly fierce competition, customer demand continues to increase. In the course of eating consumers are search for an experience. And the restaurant environments are becoming increasingly important. Restaurant as a typical representative for dining, some scholars began to focus on the restaurant's background music. The psychologist Dir. North from Lancet University of British by a new study "restaurant music" found that different music might have unintended effects on customers eating wish [9, $10]$.

In fact, the study of the relationship between music and the people first is beginning with the emotional effects of music on people, then emotions lead to changes in attitudes, and attitude determines behaviour, in order to predict the relationship between music and behaviour. Existing literature, many studies are based on different elements of the music as a starting point to study the emotional impact of music on people. But the music elements on classification, did not give a clear definition of study.

\section{DATA PROCESSING METHOD}

\subsection{Mean}

In mathematics, mean has several different definitions depending on the context.

In probability and statistics, mean and expected value are used synonymously to refer to one measure of the central tendency either of a probability distribution or of the random variable characterized by that distribution. In the case of a discrete probability distribution of a random variable $\mathrm{X}$, the mean is equal to the sum over every possible value weighted by the probability of that value; that is, it is computed by taking the product of each possible value $\mathrm{x}$ of $\mathrm{X}$ and its probability $\mathrm{P}(\mathrm{x})$, and then adding all these products together, giving

$\mu=\sum x P(x)$

\subsection{Standard Deviation}

In statistics, the standard deviation (SD) (represented by the Greek letter sigma, $\sigma$ ) is a measure that is used to quantify the amount of variation or dispersion of a set of data values.

Let $\mathrm{X}$ be a random variable with mean value $\mu$ :

$$
E[X]=\mu
$$

Here the operator $\mathrm{E}$ denotes the average or expected value of $X$. Then the standard deviation of $X$ is the quantity.

$$
\begin{aligned}
\sigma & =\sqrt{E\left[(\mathrm{X}-\mu)^{2}\right]}=\sqrt{E\left[\mathrm{X}^{2}\right]+E[-2 \mu X]+E\left[\mu^{2}\right]} \\
& =\sqrt{E\left[\mathrm{X}^{2}\right]-2 \mu E[X]+E\left[\mu^{2}\right]} \\
& =\sqrt{E\left[\mathrm{X}^{2}\right]-2 \mu^{2}+\mu^{2}}=\sqrt{E\left[\mathrm{X}^{2}\right]-\mu^{2}} \\
& =\sqrt{E\left[\mathrm{X}^{2}\right]-\left(E[\mathrm{X})^{2}\right.}
\end{aligned}
$$

In the case where $\mathrm{X}$ takes random values from a finite data set $\mathrm{x} 1, \mathrm{x} 2, \ldots, \mathrm{xN}$, with each value having the same probability, the standard deviation is

$$
\sigma=\sqrt{\frac{1}{N} \sum_{i=1}^{N}\left(x_{i}-\mu\right)^{2}} \text { Where } \mu=\frac{1}{N} \sum_{j=1}^{\pi} x_{j}
$$

If, instead of having equal probabilities, the values have different probabilities, let $\mathrm{x} 1$ have probability $\mathrm{p} 1$, $\mathrm{x} 2$ have probability $\mathrm{p} 2$, and have probability pan. In this case, the standard deviation will be

$$
\sigma=\sqrt{\sum_{i=1}^{\pi} \mathrm{p}_{j}\left(\mathrm{C}_{x_{j}}-\mu\right)^{2}} \text { Where } \mu=\frac{1}{N} \sum_{j=1}^{\pi} p_{j} \mathrm{\square} \mathrm{x}_{j}
$$

\section{EXPERIMENTAL METHODS AND RESULTS}

\subsection{Experimental Methods}

Since the study sites of this experiment was the school's restaurant, so it belongs to the field experiment. The subjects were randomly selected. The methods of the study were the scene of random experimentation field experiments.

In this article the survey places is a university restaurant. Restaurant manager is a teacher from Tourism School and service personnel are college student. Before the experimental investigation, communicate to the total charge, restaurant assistant and restaurant manager and listen to their views, get their approval and support. Under their help, train our laboratory assistant (internship attendant). In the data collection process, the author has been in the field. Before the formal experiments carried out preliminary experiments, supervised laboratory assistant, and correct experiments behavioural biases. Formal experiment was from 2015 January 1 to February 1 , continuing for one month. Collected 54 valid samples with no music, 60 valid samples with slow-paced music and 58 valid samples with fast-paced music. Use SPSS to descriptive statistics analysis the data (mean, maximum and minimum confidence level), for the preliminary understanding of the different musical rhythms impact on customer wait time.

\subsection{Experimental Results}

Statistical data of experiments are shown in Tables $\mathbf{1}$ and 2. Table $\mathbf{1}$ is the result of descriptive statistics of customer waiting time. And Table $\mathbf{2}$ is customer waiting time of weekdays and weekends.

The mean waiting time of the slow-paced group is greater than the customer waiting time of no music group, and is obviously greater than the customer waiting time of fastpaced music group. The mean waiting time of the fast-paced group is obviously less than the customer waiting time of no music group as shown in Fig. (1).

Customer waiting time of slow-paced group is up to 58 minutes, followed by the non-musical group with 42 minutes, and the lowest is fast-paced musical group with 32 minutes as shown in Fig. (2). Overall, customer wait time tolerance threshold of this restaurant is large. The reasons may be: (1) Subjects go to this restaurants more frequently, known the fact that restaurant serving is slow; (2) Subjects 
Table 1. Descriptive statistics of customer waiting time.

\begin{tabular}{|c|c|c|c|c|c|}
\hline Music Type & Customers Number & Min & Max & Mean & Standard Deviation \\
\hline \hline No music & 54 & 3 & 42 & 22.5 & 1.25 \\
\hline Slow-paced & 60 & 6 & 38 & 15.8 & 1.74 \\
\hline Fast-paced & 58 & 4 & & & 1.28 \\
\hline Total & 172 & & & \\
\hline
\end{tabular}

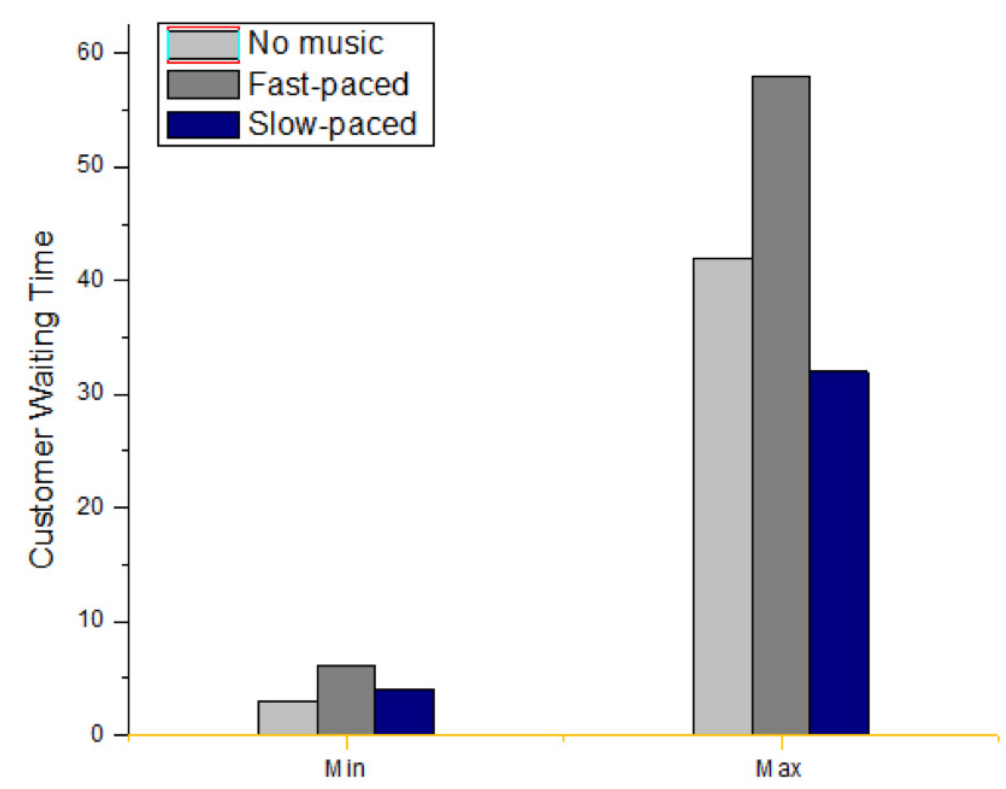

Fig. (1). The min and max value of customer waiting time for different music types.

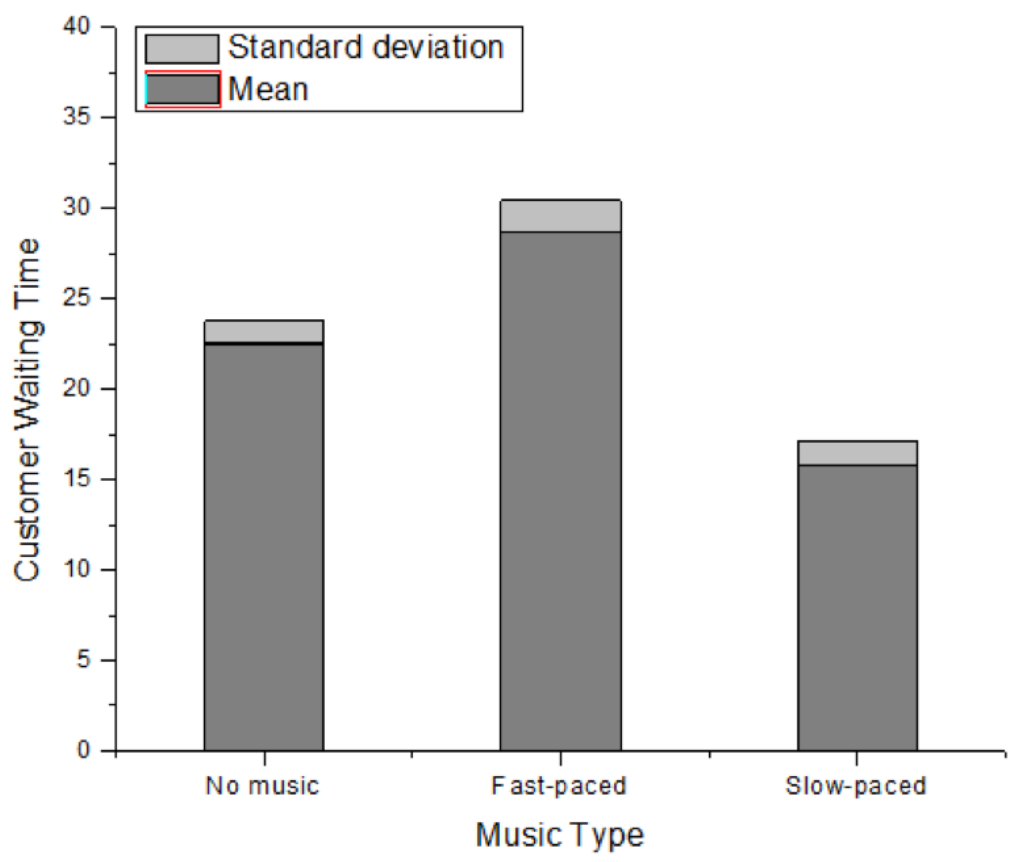

Fig. (2). The mean and standard deviation of customer waiting time for different music types. 
Table 2. Customer waiting time of weekdays and weekends.

\begin{tabular}{|c|c|c|}
\hline Music Type & Weekdays & Weekends \\
\hline \hline No music & 21.81 & 25.45 \\
\hline Slow-paced & 27.34 & 30.18 \\
\hline Fast-paced & 10.28 & 14.59 \\
\hline
\end{tabular}

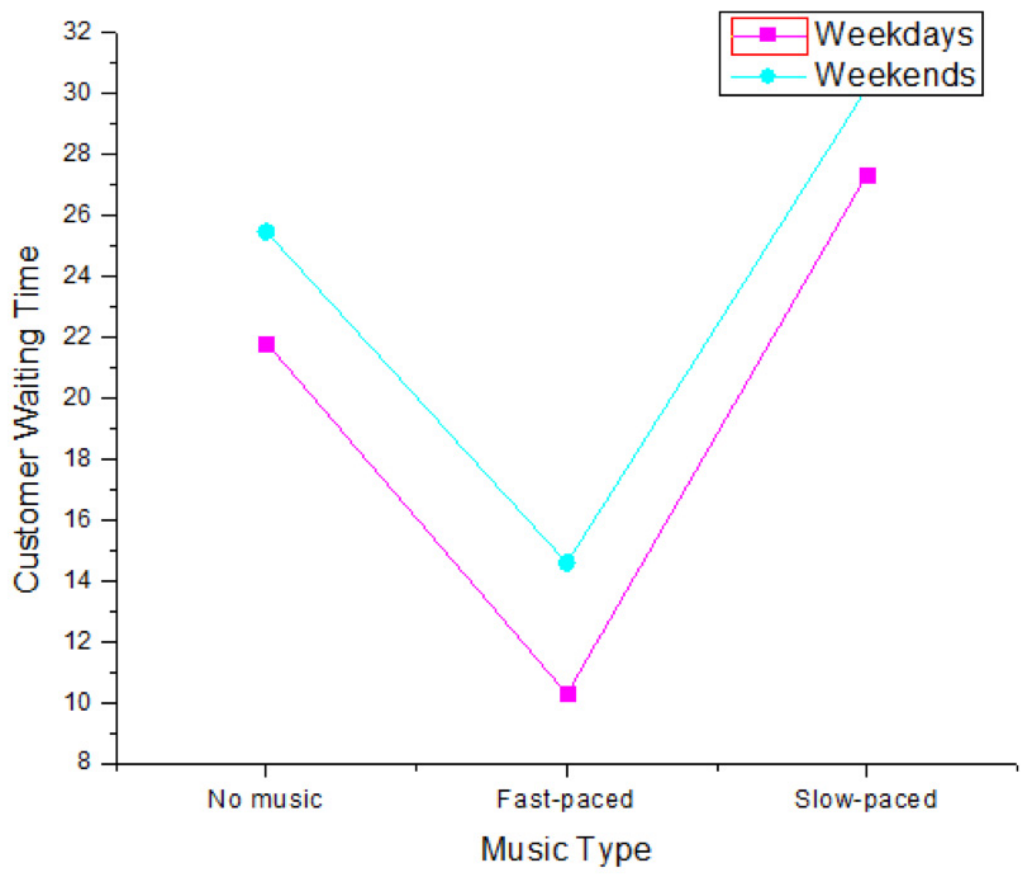

Fig. (3). Customer waiting time of weekdays and weekends.

dining to this restaurant is mainly due to the restaurant's dining environment, and the food tastes is better than the school cafeteria; (3) Working or living place of subjects is close to the restaurant; (4) Subjects have enough time to eat; (5) Subjects are at least one person for lunch, usually two to four people to eat together.

In the weekend (Saturday and Sunday), the waiting time of subjects in each group is slightly increased. This may be due to the weekend time ample. Diners eat together with family or friends, feel good relaxed, shortening its perceived waiting time as shown in Fig. (3).

$\mathrm{P}$ values after multiple comparisons of slow-paced music, fast-paced music and no music are all less than 0.05, suggested that the music and no music on customer wait times were significantly different. Combined Table $\mathbf{2}$ to analysis showed that the customer waiting time of low-paced music has significant differences to the customer waiting time of fast-paced music and no music. That slow-paced music significantly affect the customer's waiting time, having obviously mitigation for a restaurant serving slow. Combined Table 2 to analysis showed that the customer waiting time of fast-paced music has significant differences to the customer waiting time of slow-paced music and no music. That fastpaced music significantly affect the customer's waiting time, having obviously negative impact for a restaurant serving slow.

\section{CONCLUSION}

In this paper, we used experimental methods to study the impact of the background music on customer waiting time. The results show that music does affect the waiting time for customers. Slow-paced music increases latency customers. Fast-paced music will reduce customer waiting time. During the study, also found that weekend customer tolerable waiting time is longer than the working day. In this paper, combined the theory of customer waiting time, wake-up theory and time perception theory, analysed the reason for the results produced. During the experiment, the researcher himself at the scene led and supervised the experimental data recorder recording data, minimizing the error data collected. And in the data analysis, we excluded cases with missing values. Therefore, the conclusions of this study have internal validity. The experiment was done in the school experiment restaurant. The restaurant has the following characteristics: Located within the school; Source to students, school teachers and their families, supplemented by outside sources; better environment than the school canteens. Other school restaurants are generally consistent with the experimental restaurant. Therefore, the conclusion of this study has reference significance to other restaurant above with an external validity.

Inadequacy of research: Since this study did not study the outside restaurant, therefore, only applying to the school 
restaurant, which has a small range; Experiments of this type is randomized experimental in scene, controlling experiments with some difficulty and the data collected will have a certain bias; Due to conditions, this experiment did not classify customers.

\section{CONFLICT OF INTEREST}

The author confirms that this article content has no conflict of interest.

\section{ACKNOWLEDGEMENTS}

This work is supported by the Key Project of Guangxi Social Sciences, China (No. gxsk201424), the Education Science fund of the Education Department of Guangxi, China (No. 2014JGA268), and Guangxi Office for Education Sciences Planning, China (No. 2013C108).

\section{REFERENCES}

[1] J.I. AIPert, and M.I. AIPert, "Music influences on mood and purehase intentions," Psychology and Marketing, vol. 7, no. 2, pp. 109133, 2006.
[2] J. Baker, and M.Cameron, "The effects of the service environment on affect and consumer perception of waitting time: An integrative review and research propositions, "Journal of the Academy of Marketing Science, vol. 24, no. 4, pp. 338-649, 2009.

[3] M. Nederland, "In-store muse and consumer-brand relationships: relational Transformation following experiences of (miss) fit," Journal of Business Research, vol. 59, no. 9, pp. 982-989, 2006.

[4] G.C. Bruner, "Music, mood, and marketing,"The Journal of Marketing, vol. 54, no. 4, pp. 94-104, 1990.

[5] S.A. Errol, K. Maehleit and T.F. Barr, "Perceived retail crowding and shopping satisfaction: the role of shopping values," Journal of Business Research, vol. 58, no. 8, pp. 1146-1153, 2010.

[6] G.D. Harrell, M.D. Hutt and J.C. Anderson, "Path analysis of buyer behaviour under conditions of crowding," Journal of Marketing Research, vol. 17, no. 1, pp. 45-51,2008.

[7] J. Horne, "Subjective vs. objective time measures: A note on the perception of time in consumer behaviour," Journal of Consumer Research, vol. 11, no. 1, pp. 615-618, 2009.

[8] D. Moister, "The Psychology of Waiting in Lines," The Service Encounter: Managing Employees/customer Interaction in Service Business, 2005.

[9] W. Nye, "Waiting: Integrating social and psychological perspectives in operations management. Omega," Journal of Consumer Research, vol. 28, no. 6, pp. 611-629, 2010.

[10] G. Tom, and S.Lucy, "A field study investigating the effect of waiting time on customer satisfaction," Journal of Psychology, vol. 131 , no. 6, pp. 655-660, 2011. 